\title{
Environmental conditions and life history constraints determine foraging range in breeding Adélie penguins
}

\author{
Judy Clarke ${ }^{1, *}$, Louise M. Emmerson ${ }^{1}$, Petr Otahal $^{2}$ \\ ${ }^{1}$ Department of the Environment and Heritage, Australian Antarctic Division, 203 Channel Hwy, Kingston, Tasmania 7050, \\ Australia \\ ${ }^{2} 35$ Seventh Ave, West Moonah, Tasmania 7009, Australia
}

\begin{abstract}
Foraging movements of Adélie penguins are constrained both by environmental conditions (e.g. sea ice cover) and life history factors (e.g. regular offspring provisioning). We describe within season changes in foraging range, trip duration and body condition of Adélie penguins nesting at Béchervaise Island, East Antarctica, in the context of these constraints. Penguins were satellite tracked over multiple seasons during the incubation, guard, crèche and pre-moult phases of their annual cycle. They ranged farthest during incubation when sea ice was extensive and shortest during the guard stage when chicks were small and sea ice limited in extent. Prior to their annual moult the birds foraged hundreds of kilometres to the west and east of their breeding sites. A recurrent polynya facilitated access to the sea early in the season when ice cover was extensive. Kernel analyses showed that penguins foraged most intensively close to the colony, along submarine canyons and at the continental shelf break. Increases in foraging range, as the chick rearing period progressed, were consistent with changing energy requirements of adults and chicks and likely intraspecific competition. Whilst provisioning their offspring, penguins adopted a variable combination of time minimising and food maximising foraging behaviour in which choice of foraging rule was determined largely by adult body condition.
\end{abstract}

KEY WORDS: Satellite tracking $\cdot$ Pygoscelis adeliae $\cdot$ Foraging range $\cdot$ Chick provisioning $\cdot$ Body condition $\cdot$ Kernel analysis · Polynya

\section{INTRODUCTION}

Foraging strategies of breeding seabirds involve tradeoffs between self maintenance and offspring provisioning (Ydenberg et al. 1994). Penguins are central place foragers (Orians \& Pearson 1979) whose foraging range is constrained during the breeding season by a variety of extrinsic and intrinsic factors (Stephens \& Krebs 1986). Extrinsic constraints include physical barriers such as sea ice, proximity of prey concentrations to nesting sites and competition with other species and individuals. Intrinsic constraints include physiological capabilities, the requirement to return to the colony regularly to carry out incubation and chick feeding duties, and the basic necessity of maintaining body condition above certain threshold levels.
There are 2 currencies by which foraging behaviour can maximise the overall net rate of energy gain: (1) minimising the time taken to obtain a fixed amount of energy (time minimisation) and (2) maximising the amount of energy gained in a fixed amount of time (energy maximisation) (Schoener 1971, Stephens \& Krebs 1986). While the 2 currencies are equivalent in terms of overall rate maximisation (Pyke et al. 1977), the currency appropriate to a given situation depends on whether time or energy is most constrained. Central place foragers may aim to: (1) minimise time away from the colony when food is available nearby, thereby allowing regular feeding of offspring, or (2) maximise energy intake regardless of time away, thus enabling access to distant dense prey resources. A combination of both strategies may facil- 
itate partitioning of resources between reproduction and self maintenance in environments where the location and accessibility of prey resources are variable or when intra-specific competition for food is a limiting factor. A dynamic penguin-krill modelling study by Alonzo et al. (2003) demonstrated that penguin foraging rules (food maximising vs time minimising) can strongly affect their predicted at-sea distribution in a system where prey is available both inshore and offshore. In this dynamic predator-prey model, penguins adopting a time-away-from-colony minimising strategy foraged close to the colony while penguins maximising food intake were more likely to forage further away.

In this paper we show how Adélie penguin foraging ranges vary as the breeding season progresses and discuss these changes in the context of environmental conditions and life history constraints. We demonstrate a strong correlation between foraging trip duration and foraging range, and use an extensive multi-year set of foraging duration and weight data to further investigate foraging strategies during the guard and crèche stages when penguins must finely balance chick provisioning and self maintenance. We investigate whether Adélie penguins adopt time minimising and/or food maximising foraging rules during chick rearing and discuss how flexible use of these strategies helps this species to survive in a variable physical environment.

\section{MATERIALS AND METHODS}

Field site and study animals. The Adélie penguin colony on Béchervaise Island $\left(67^{\circ} 35^{\prime} \mathrm{S}, 62^{\circ} 49^{\prime} \mathrm{E}\right)$ near Mawson station East Antarctica, has been monitored annually since 1990-91 (Kerry et al. 1997, Clarke et al. 2002, 2003). This colony of 2000 breeding pairs is among a complex of colonies totalling approximately 55000 pairs located along a $10 \mathrm{~km}$ stretch of the coastline (Woehler 1993, Woehler et al. 2001). Much of the work on this island has been carried out using a custom built Automated Penguin Monitoring System (APMS) that records the weights and times of departure and arrival of individually tagged penguins from the colony (Kerry et al. 1993, Clarke \& Kerry 1998).

Satellite tracking of foraging Adélie penguins has been carried out over a number of years, covering all stages of the breeding season (incubation, guard, crèche and pre-moult). Here we collate tracking data collected during the 1991-92 to 2002-03 austral summers to obtain an overview of foraging movements during each of these periods. We also analyse coincident APMS data collected during the guard and crèche stages to determine relationships between adult body condition and foraging trip duration. Individual penguins were tracked over multiple foraging trips during the guard and crèche periods but only for single trips during incubation and pre-moult stages (Table 1).

A small number of penguins tracked during the late crèche period failed to return in some seasons and instead remained at sea prior to carrying out their annual moult. Tracks from these birds were collated separately as an indication of pre-moult foraging movements post-breeding. It was acknowledged that the behaviour of these birds might not be fully representative of successful breeders, which commence premoult foraging trips later in the season. All birds tracked prior to the moult stage were observed alive and breeding in subsequent seasons.

Trip durations and departure weights of foraging penguins were determined from APMS data as described in Clarke et al. (2002). Only foraging trips from known-sex adults that were feeding chicks were included, and data were restricted to trips commencing prior to the end of January each year (to be compatible with the tracking data set). Sex was determined by cloacal examination (Sladen 1978) at the time of initial tag implantation.

Instrument deployment and processing of location data. All penguins were tracked using platform terminal transmitters (PTTs) of three different makes and models. Toyocom T-2038 and Telonics ST-6 and ST-10 PTTs were used between 1991 and 1999, weighing 100 and $120 \mathrm{~g}$, respectively, and with frontal crosssectional areas of approximately $7 \mathrm{~cm}^{2}$. From 2000 onwards Kiwisat 101 PTTs (Sirtrack) were utilised; these weigh $90 \mathrm{~g}$ and have a frontal cross-sectional area of $3.75 \mathrm{~cm}^{2}$. All PTTs were packaged by Sirtrack to withstand diving to $200 \mathrm{~m}$, and shaped to minimise hydrodynamic drag.

Table 1. Number of penguins tracked from Béchervaise Island each year at each stage, and the number of foraging trips undertaken in each category

\begin{tabular}{|c|c|c|c|c|c|c|c|c|}
\hline & \multicolumn{2}{|c|}{ Incubation } & \multicolumn{2}{|c|}{ Guard } & $\begin{array}{l}\text { Crè } \\
\text { Birds }\end{array}$ & Crèche & \multicolumn{2}{|c|}{ Pre-moult } \\
\hline 1991-92 & 3 & 3 & 2 & 6 & 4 & 12 & & \\
\hline $1992-93$ & & & 8 & 9 & 2 & 5 & & \\
\hline $1993-94$ & & & 8 & 23 & 7 & 20 & 4 & 4 \\
\hline 1994-95 & & & 7 & 12 & & & & \\
\hline 1995-96 & & & 6 & 12 & & & 1 & 1 \\
\hline $1996-97$ & & & 6 & 48 & 5 & 18 & & \\
\hline $1997-98$ & 4 & 4 & 5 & 18 & & & & \\
\hline 1998-99 & 4 & 4 & 7 & 13 & 5 & 7 & & \\
\hline $1999-00$ & 3 & 3 & 8 & 21 & 4 & 4 & 1 & 1 \\
\hline $2000-01$ & 7 & 7 & 21 & 67 & 13 & 15 & 3 & 3 \\
\hline 2001-02 & & & 9 & 20 & 2 & 3 & 1 & 1 \\
\hline $2002-03$ & & & 10 & 27 & 6 & 6 & 3 & 3 \\
\hline
\end{tabular}


Instruments were attached to the penguins' lower back using glue (Loctite $401^{\circledR}$ ) and cable ties as described by Kerry et al. (1995a), except that transmitters were glued directly to the feathers after 1993. Devices were deployed on penguins of known breeding status and sex and removed at the end of the tracking period (except pre-moult birds). Durations of attachment ranged from 12 to $34 \mathrm{~d}$ during incubation (single trips), 1 to $31 \mathrm{~d}$ during chick rearing (median 2 trips, range 1 to 26 trips) and 9 to $31 \mathrm{~d}$ during the pre-moult period (single trips).

Location data were provided by ARGOS and processed using custom software from the Australian Antarctic Division. Only class 1, 2 and 3 fixes (estimated accuracy within 1000 m; Service Argos 1996) were used for plots of foraging locations, and these were filtered to remove any fixes that required birds to swim at speeds $>12 \mathrm{~km} \mathrm{~h}^{-1}$ between locations, as such speeds are unlikely to be maintained over long periods (Culik et al. 1994). Start and end times of foraging trips were determined by the APMS (details of transponder implantation and APMS function are provided in Kerry et al. (1993) and Clarke \& Kerry (1998). In cases where APMS data were unavailable, start and end times of trips were estimated from a combination of twice daily nest observations and ARGOS data (fixes received every $1.9 \pm 0.04 \mathrm{~h}$ ).

Maximum distance reached was calculated as the straight line distance from the colony to the most distant location received during each trip. Of the 366 trips made during chick rearing 22 were not allocated a maximum distance either because the trip was too short for more than one class 1 to 3 fix to be received, or because data were received too intermittently for the bird's turn around point to be estimated with any level of certainty. The latter problem only occurred in the first few seasons due to occasional instrument malfunction or failure part way through a trip.

At sea location data were imported into Geographical Information Systems Software ArcGIS $^{\circledR}$ V8.0 and ArcView $^{\circledR}$ V3.3) and plotted together with bathymetric contours and sea ice data. Bathymetry was derived from the Prydz Bay 1:500000 Bathymetric GIS Dataset (Ryan 1999) and the General Bathymetric Chart of the Oceans (GEBCO) Digital Atlas, Centenary Edition 2003. Ice images were acquired from the Advanced Very High Resolution Radiometer (AVHRR) carried on National Oceanic and Atmospheric Administration (NOAA, USA) satellites, collated by Michael et al. (2003).

Kernel analyses and statistical models. Location data were divided into fast and slow categories depending on whether the mean speed of travel from the previous location and to the next location was $>4$ or $<4 \mathrm{~km} \mathrm{~h}^{-1}$, this being low in the range of speeds utilised by Adélie penguins travelling in a swim canal
(Culik et al. 1994). Kernel density distributions were produced for location data in the $<4 \mathrm{~km} \mathrm{~h}^{-1}$ category based on the assumption that birds travelling slowly between locations were likely to be actively foraging while those moving faster were more likely to be commuting between the colony and feeding grounds. The cut off speed of $4 \mathrm{~km} \mathrm{~h}^{-1}$ removed 19, 37 and $42 \%$ of fixes in incubation, guard and crèche phases respectively. Fixed kernel estimation techniques (Worton 1989) were performed using the Animal movement extension to ArcView $^{\circledR}$ (Hooge \& Eichenlaub 1997), available at www.absc.usgs.gov/glba/gistools/, and included ad hoc calculation of the smoothing parameter (Silverman 1986), considered robust with large sample sizes (Hooge \& Eichenlaub 1997). Probability polygons of foraging density were produced showing 55, 65, 75, 85, and $95 \%$ isopleths. Kernel areas were calculated in a Lazimuth Equal Area south polar projection. ARGOS fixes closer than $40 \mathrm{~km}$ to the colony were omitted in the incubation stage because the birds had to cross this distance of fast ice on foot before feeding could commence.

Maximum distance-from-colony data were compared among breeding stages using individual bird means as the sampling unit to reduce the skewed nature of the distribution of maximum distances for individual trips, which was due to some birds making multiple short trips over the same time period taken by other individuals to carry out fewer longer trips. The non-parametric median test was used to analyse differences in foraging range among breeding stages because the distributions of maximal distances in both the guard and crèche stages were bimodal as well as skewed.

Statistical analyses of APMS derived data were performed on an individual trip basis to investigate: (1) the relationship between foraging trip duration and departure weight during guard and crèche phases, (2) the relationship between departure weight and chronological date of departure within the guard and crèche stages, and (3) the relationship between foraging trip duration and chronological date (relative to median hatch and crèche dates) within the two stages. In conjunction the 3 analyses were designed to disclose the rate at which parents lose or gain body condition after their chicks hatch, how this rate varies between the two stages of chick rearing, and whether the need of parents to forage for themselves in addition to their offspring affects their foraging range. Short trips and simultaneous loss of parental mass was believed to indicate use of a time minimising strategy in which investment in chick provisioning outweighs self maintenance. In contrast, food maximising behaviour was deemed more likely to manifest as longer foraging trips and an increase or maintenance of parental mass. 
Statistical models were fitted separately for the guard and crèche stages of chick rearing in all three analyses. Linear random-effects regression models were used, incorporating different intercepts and slopes for individual penguins. Sex and season were included as fixed effects and individual penguins as random effects. Correlations between successive trips by individual birds were accommodated by fitting an autocorrelation (AR1) component into each model. In all analyses the fitting of models was a sequential process in which the most complex model was fitted first and terms were progressively removed one by one until the simplest model that fitted the data was determined. Tests for interaction terms were always undertaken ahead of tests for individual effects and where interactions were retained so too were the corresponding main effects.

All analyses employed restricted maximum likelihood estimation (REML) methodology, and calculations were performed in the statistical computing package 'R' (www.r-project.org). Normality of random components was examined using QQ plots. Foraging trip duration data were log transformed to meet normality and equality of variances requirements. Consequently, group comparisons were based on ratios rather than differences among means, and linear relationships on the logarithmic scale became exponential relationships on the original scale of measurement. All variables other than foraging trip duration were untransformed.

To test for possible adverse effects of instrumentation (Watanuki et al. 1992, Hull 1997, Taylor et al. 2001), foraging trip durations of birds carrying PTTs during the chick rearing period were compared with those of a set of non-instrumented birds whose foraging trips were monitored by the APMS. To avoid differences due to sex (Clarke et al. 1998) and to randomise selection with respect to trip duration whilst controlling for date and time of day, each control trip selected was that of a bird of the same sex as the PTT carrier whose exit from the colony was recorded immediately subsequent to the departure of the instrumented bird. Trip durations of PTT carriers and controls were compared within years by Mann-Whitney rank sum tests.

\section{RESULTS}

\section{Distribution of foraging birds in relation to sea ice and bathymetry}

Clear differences in foraging range among the four stages of the breeding season were apparent and are illustrated in Fig. 1. Median maximal distances from the colony reached by foraging birds were 272, 60, 125 and $380 \mathrm{~km}$ in the incubation, guard, crèche and premoult stages of breeding respectively for all years pooled (Table 2a). Differences in maximum distances reached were significant between all pairs of breeding stages apart from incubation and pre-moult (Table $2 b$ ). Penguins from Mawson travelled to the vicinity of other major neighbouring populations (Fig. 1), especially during the pre-moult period.

The results of kernel analyses during the incubation, guard and crèche stages overlaying bathymetric contours in the region north of the colony are displayed in Fig. 2. Densities were greatest near the colony and over the steep continental shelf break. Foraging areas within the $55 \%$ isopleth covered 9977, 238 and $634 \mathrm{~km}^{2}$ during incubation, guard and crèche periods respectively, while within the $95 \%$ isopleth ranges covered 79164,1782 and $18039 \mathrm{~km}^{2}$ for the same 3 stages of the breeding cycle.

Birds foraged furthest north during the incubation period when pack ice was extensive. Foraging was concentrated over the continental slope region northwest of the colony (Fig. 2a), as well as in ice covered areas to the north and south. Incubation stage trips were superimposed onto ice images taken when females (Fig. 3a) and males (Fig. 3b) were at sea. The position of the fast ice edge was remarkably constant between seasons (Michael et al. 2003), as was the obvious polynya situated between 60 and $62^{\circ} \mathrm{E}$, which penetrates the fast ice as far south as $67^{\circ} 10^{\prime} \mathrm{S}$ by late November each year. A striking feature of the penguin tracks, particularly females, was the birds' propensity to travel directly to the southern margin of the polynya on their outward journeys. Upon reaching the polynya the penguins travelled around its eastern edge before heading northwards into the pack ice to forage. Distances and directions of travel once in the pack ice varied among individuals. Sample sizes were too small to test whether these differences were due to season or sex or whether they were purely due to variation among individuals. Consistent among years, however, was the use of the polynya for access to the water and a preference for foraging amongst the pack ice rather than in the open water of the polynya.

Foraging distances were shortest in the guard stage when birds travelled as far north as the continental shelf break but rarely beyond (Fig. 1, Table 2). In this period penguins return regularly to their nests to feed small chicks and swap brooding duties with their partners. The fast ice breaks out during the guard stage in most seasons, providing access to open water throughout much of the chick rearing period. Birds foraging during the guard stage concentrated most of their activity within 15 to $20 \mathrm{~km}$ of the colony, although some also focussed on a relatively localised 


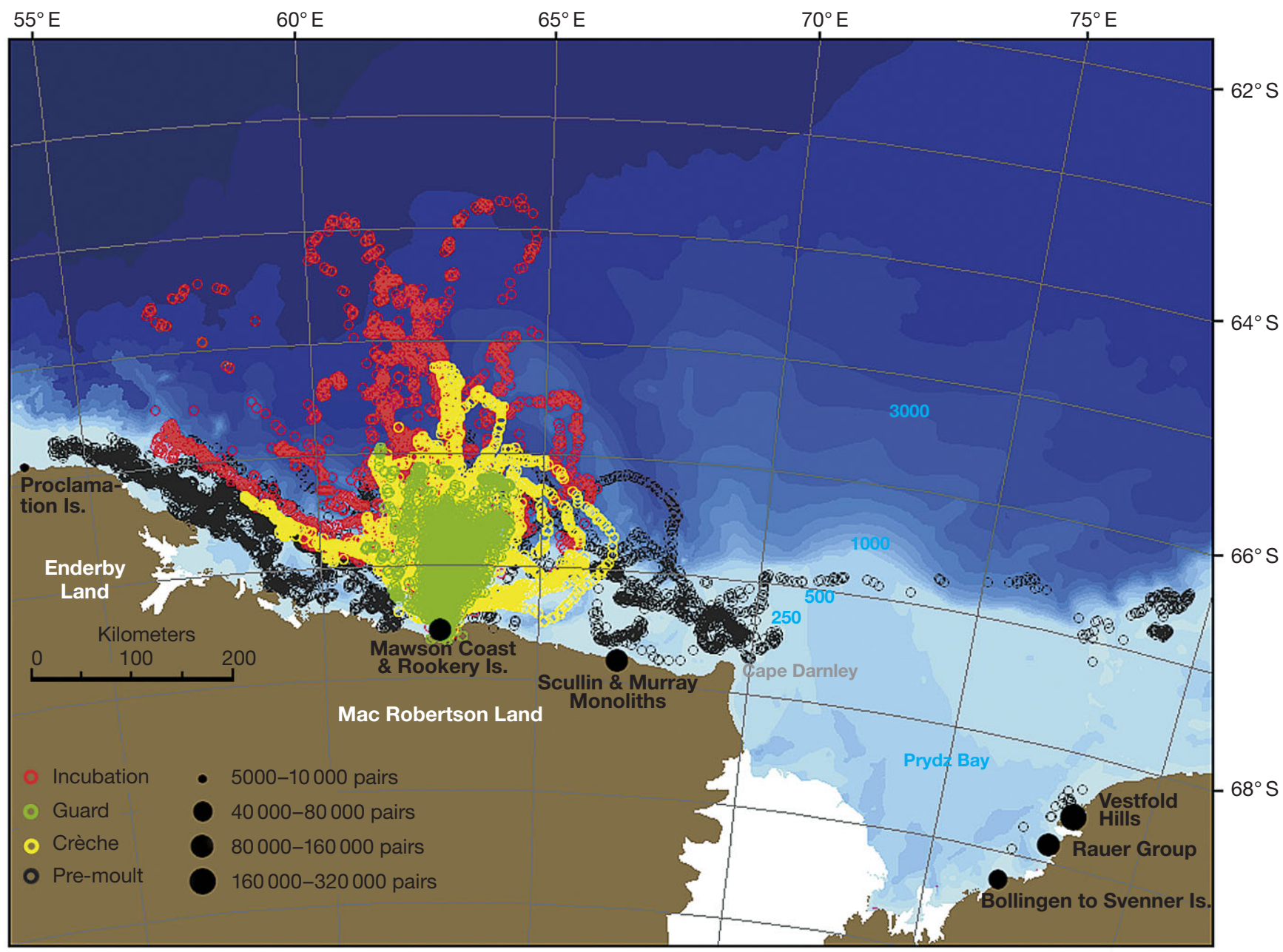

Fig. 1. Pygoscelis adeliae. Fixes from all birds tracked from 1991 to 2003 at Béchervaise Island. Colours indicate stage of breeding (see legend on figure). Bathymetric contours are at $250 \mathrm{~m}$ intervals. Major breeding populations of Adélie penguins along the coast are indicated

Table 2. (a) Median foraging distances from the colony for each stage of breeding (all seasons pooled). Median, lower and upper quartile values are provided for all trips during incubation and pre-moult, and all bird means during guard and crèche when individuals made multiple trips. (b) Results of Dunn's pairwise comparisons of bird means among stages following median test $($ median $=99.0$, Chi-square $=74.857, \mathrm{df}=3, \mathrm{p}<0.001$ )

\begin{tabular}{|llcccc|}
\hline (a) Breed stage & Sampling unit & N & Median distance & $25 \%$ & $75 \%$ \\
\hline Incubation & Trips (1 per bird) & 21 & 272 & 223 & 340 \\
Guard & Bird means & 93 & 60 & 8 & 95 \\
Crèche & Bird means & 48 & 125 & 92 & 147 \\
Pre-moult & Trips (1 per bird) & 13 & 380 & 301 & 484 \\
& & & & \\
(b) Bird means & Diff. of Ranks & & & p-value \\
Pre-moult vs. Guard & 107.39 & 7.159 & $<0.001$ \\
Pre-moult vs. Crèche & 64.20 & 4.053 & $<0.001$ \\
Pre-moult vs. Inc & 11.65 & 0.652 & $<0.05$ \\
Inc vs. Guard & 95.74 & 7.822 & $<0.001$ \\
Inc vs. Crèche & 52.55 & 3.965 & $<0.001$ \\
Crèche vs. Guard & 43.19 & 4.796 & $<0.001$ \\
\hline
\end{tabular}

area over the continental shelf break 100 to $110 \mathrm{~km}$ northeast of the colony (Fig. 2b). Instead of travelling northwest towards the edge of the polynya as they did during incubation, birds provisioning chicks travelled slightly east of north along a 200 to $500 \mathrm{~m}$ deep submarine canyon towards the closest and steepest region of the continental shelf break, approximately $105 \mathrm{~km}$ from the colony.

By the crèche stage, when free to forage simultaneously, parents ranged further to the east and west of their guard stage routes, and also foraged to the north of the continental shelf with greater frequency than was the case when chicks were small (Fig. 1). Foraging was concentrated over an area up to 30 times as large as that utilized during the guard period, with heavi- 

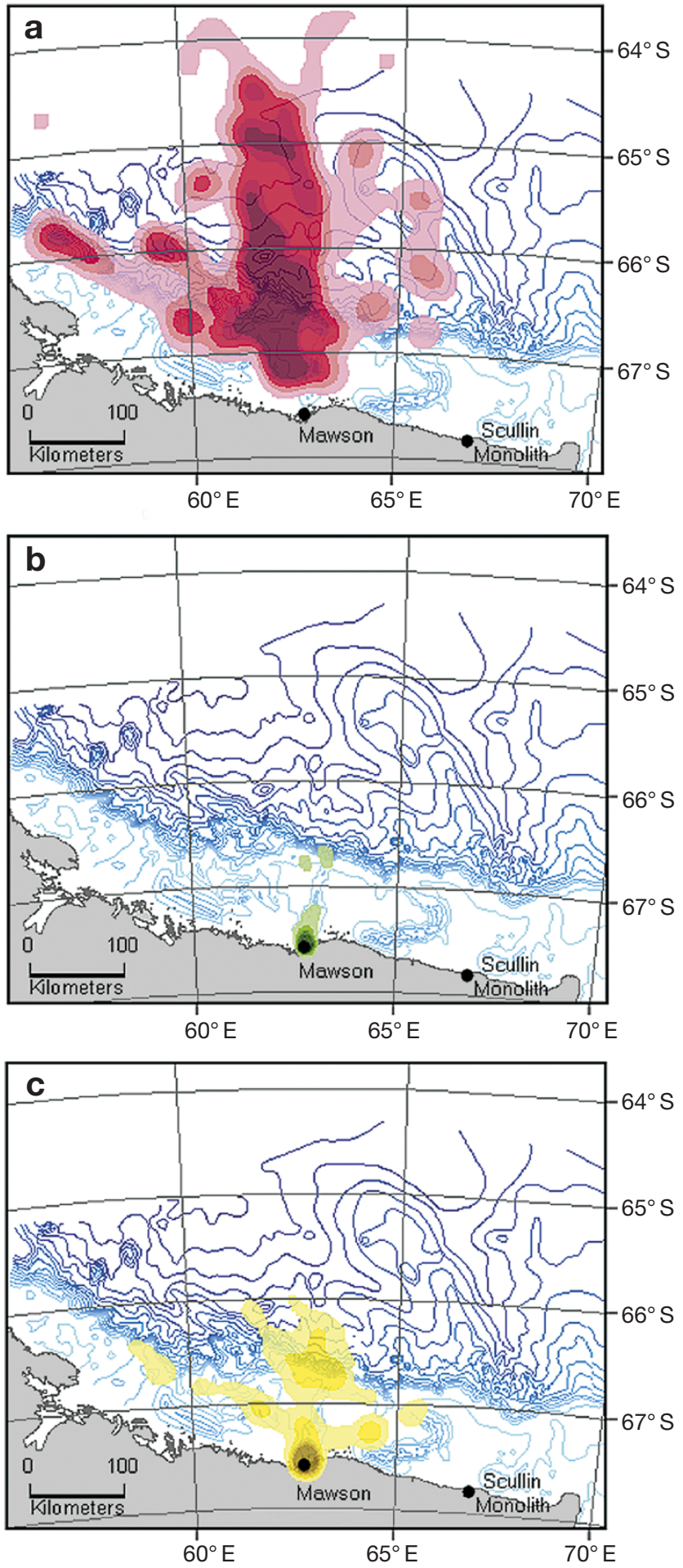

Fig. 2. Pygoscelis adeliae. Kernel analyses derived from penguins foraging offshore of Béchervaise Island in all years during the (a) incubation, (b) guard and (c) crèche stages of breeding. Intensity of shading indicates 55, 65, 75, 85 and $95 \%$ isopleths. Bathymetric contours are at $250 \mathrm{~m}$ intervals. Data were limited to fixes obtained when birds were travelling at average speeds of $<4 \mathrm{~km} \mathrm{~h}^{-1}$. The narrow submarine canyon penetrating towards the coastline is visible at the centre of the guard and crèche maps est intensity once again close to the colony and over the shelf break (Fig. 2c). Foraging in neritic waters over the shelf (now free of fast ice) was recorded, and penguins utilised a more extensive region of the shelf slope zone than earlier in the chick rearing period.

Prior to their annual moult penguins foraged even further from the colony, travelling east and west over the continental shelf and along the shelf break, but rarely moving far to the north of it (Fig. 1). At this stage birds were recorded almost as far west as Proclamation Island ( $65^{\circ} 51^{\prime} \mathrm{S}, 53^{\circ} 41^{\prime} \mathrm{E} ; 440 \mathrm{~km}$ from Mawson) and as far east as the edge of Prydz Bay $\left(79^{\circ} \mathrm{E} ; 745 \mathrm{~km}\right.$ from Mawson). PTTs carried by these individuals frequently ran out of battery power and ceased transmitting before the bird reached its location of moult; thus many of these penguins may have travelled further than determined in this study. While foraging ranges of incubation and pre-moult birds were similar, their direction of travel differed; birds foraged mainly to the north during incubation and travelled east and west over the continental shelf during the pre-moult period (Fig. 1). Fast ice is present over the continental shelf during incubation but absent during pre-moult (Michael et al. 2003).

Foraging range differences between breed stages were consistent in most years (Fig. 4), and maximum distances travelled were similar among years within the incubation, guard and pre-moult stages (KruskalWallis 1-way ANOVA on ranks: $H=4.610, \mathrm{df}=4, \mathrm{p}=$ 0.33; $H=11.426, \mathrm{df}=11, \mathrm{p}=0.408 ; H=3.731, \mathrm{df}=5$, $\mathrm{p}=0.589$ respectively). In the crèche stage the only unusual season was 2002-03 in which penguins travelled significantly further than they did in 1991-92 and 1993-94 (Dunn's pairwise comparisons: $Q=3.928$, $\mathrm{p}<$ $0.05 ; Q=4.044, \mathrm{p}<0.05$ respectively; Kruskal-Wallis 1 -way ANOVA on ranks: $H=25.443, \mathrm{df}=8, \mathrm{p}=0.001$ ). These results indicate that the differences between breed stages demonstrated in Fig. 1 are not unduly influenced by interannual variability and unbalanced sampling design.

\section{Foraging strategies in relation to body mass during chick rearing}

A significant positive relationship between foraging trip duration and maximum distance from the colony was demonstrated for foraging trips carried out by PTT carriers during chick rearing (Spearman rank correlation, $\left.\mathrm{r}_{\mathrm{s}}=0.907, \mathrm{p}<0.001, \mathrm{n}=344\right)$. The relationship is shown graphically in Fig. 5 for all seasons combined. The two variables were also significantly correlated within each of the guard and crèche stages $\left(\mathrm{r}_{\mathrm{s}}=0.886, \mathrm{p}<0.001, \mathrm{n}=261\right.$ and $\mathrm{r}_{\mathrm{s}}=$ $0.874, \mathrm{p}<0.001, \mathrm{n}=83$ respectively). Correlations 


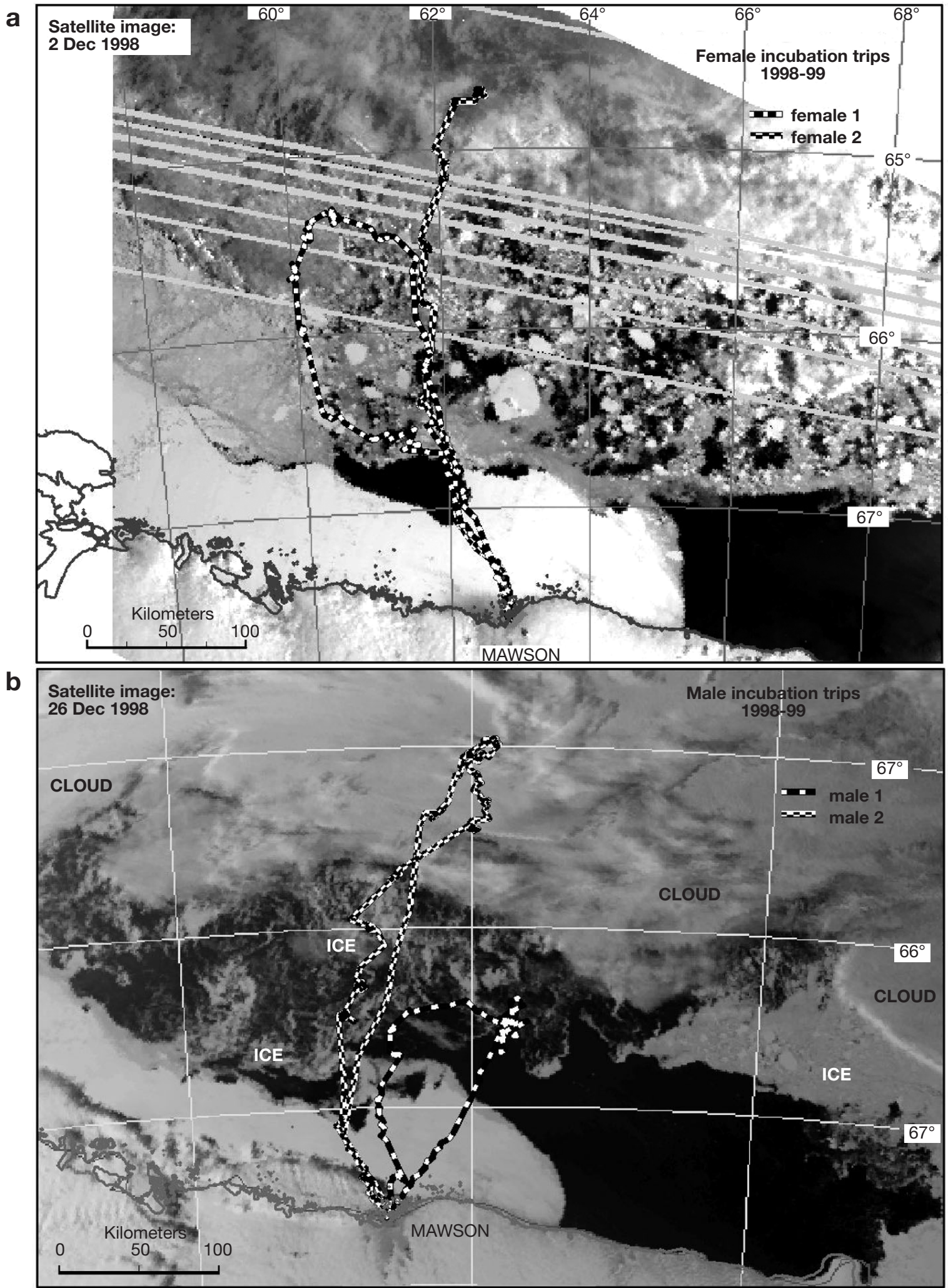

Fig. 3. Pygoscelis adeliae. Foraging trips of (a) females and (b) males during the incubation period of 1998-99. Tracks are superimposed upon AVHRR images of the sea ice during early and late December respectively. The polynya to the northwest of Mawson is a consistent feature in all seasons. Birds walked towards the polynya on their outward journey; their return routes were less consistent 


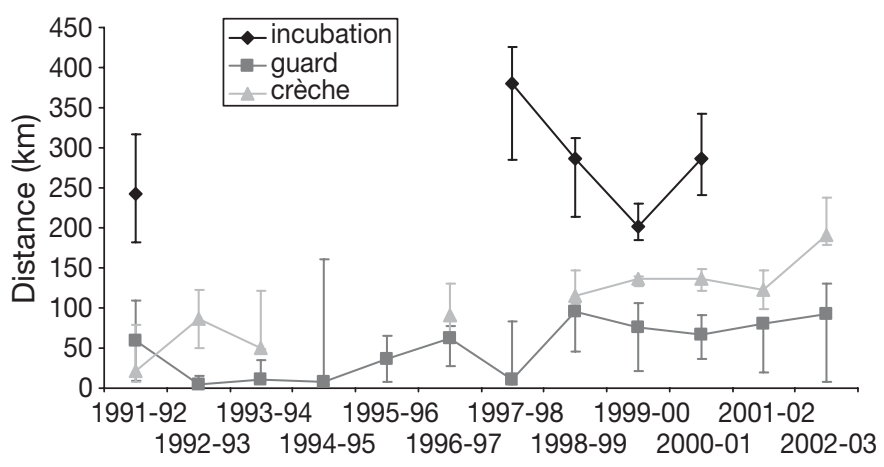

Fig. 4. Pygoscelis adeliae. Median foraging ranges for each season and stage of breeding. Bird means were used as sampling units. Error bars indicate upper and lower quartile values. The pre-moult stage was omitted because for most birds only partial journeys were recorded

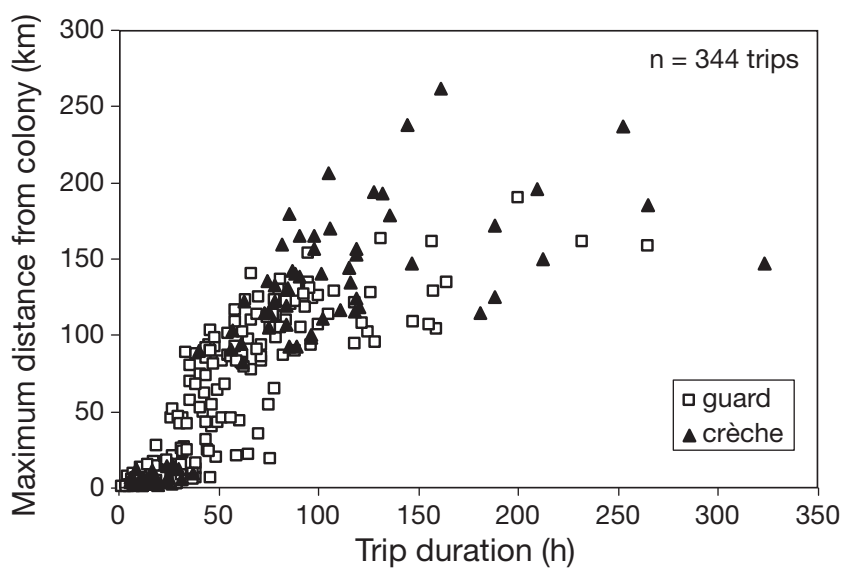

Fig. 5. Pygoscelis adeliae. Scatter plot of foraging trip duration versus maximum distance from the colony for 344 trips carried out by satellite tracked birds during the chick rearing period (guard and crèche) of all seasons combined remained significant when seasons were analysed separately $\left(\mathrm{r}_{\mathrm{s}}\right.$ ranging from 0.646 to $0.953, \mathrm{p}<0.001$ to $0.022, \mathrm{n}=10$ to 82 ). The consistently significant nature of this relationship provided confidence in the use of foraging trip duration as a surrogate for foraging distance. Apparent also in Fig. 5 is the bimodal distribution of foraging distances during the crèche stage. Penguins performed either short trips on which they remained within $30 \mathrm{~km}$ of the colony or long trips of distances 80 to $200 \mathrm{~km}$ from the coast (see also Fig. 2c). A similar bimodality in trip durations has been observed in APMS data (Clarke et al. 1998).

Foraging trips generally lengthened in proportion to a decrease in penguin body weight (Fig. 6, Table 3a). Within any year both sexes showed the same proportional rate of increase in foraging trip duration with decreasing departure weight. Females spent an estimated $31 \%$ (95\% CI: 24 to $38 \%$ ) longer foraging in the guard stage and $7 \%$ (95\% CI: 1 to $14 \%$ ) longer in the crèche stage than males. Seasonal variations were significant, but the pattern of change was the same for both sexes. For the guard stage the rate of increase in time spent foraging per $100 \mathrm{~g}$ of body weight lost varied from -0.6 to $5.2 \%$ and in the crèche stage from 0.3 to $7.7 \%$ (Table $4 \mathrm{a}$ ). These rates were significantly different from zero in all years except 1993-94, 1996-97 and 2001-02 in the guard stage and 1997-98 and 2001-02 in the crèche stage. The years in which foraging duration did not change as a function of body weight in the guard stage were the 3 seasons of highest breeding success recorded over the $12 \mathrm{yr}$ of the study (J. Clarke unpubl. data). No data were available for the crèche stage in 1994-95 because all chicks

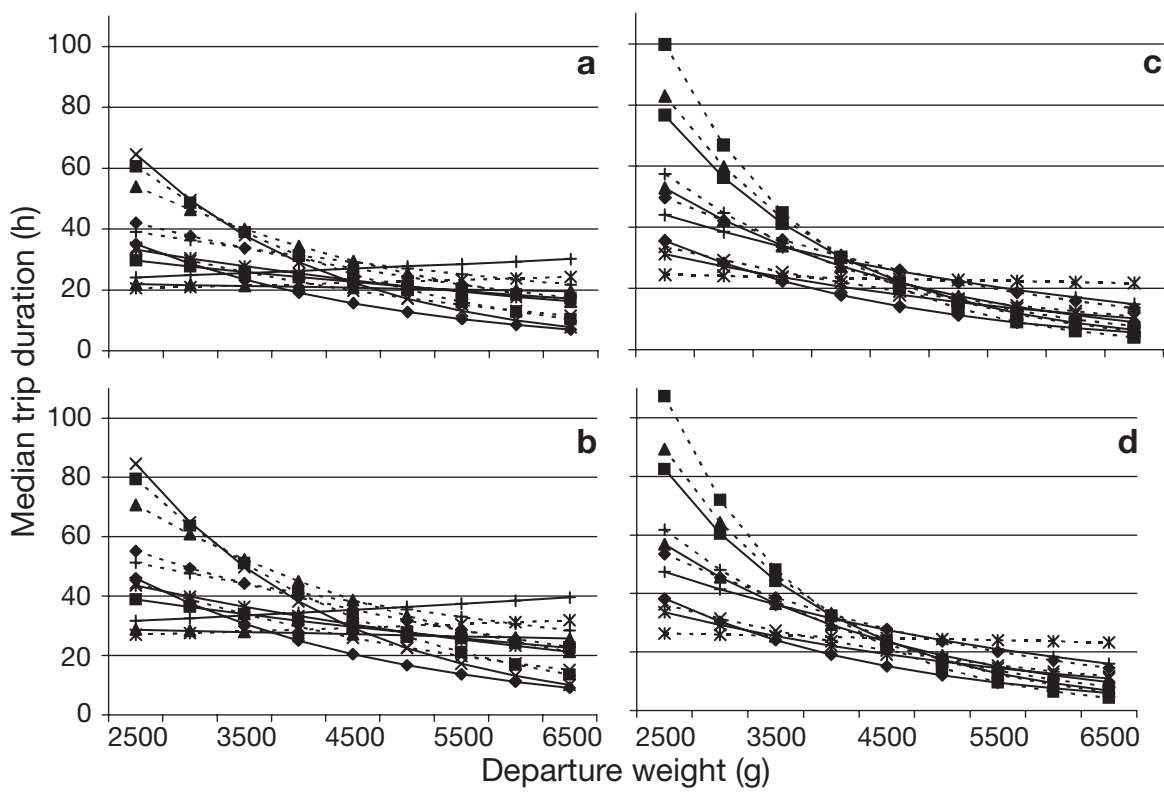

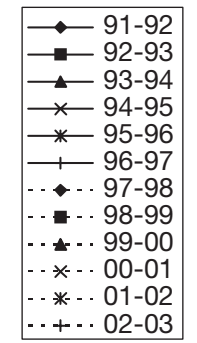

Fig. 6. Pygoscelis adeliae. Relationship between foraging trip duration and departure weight for 12 seasons of APMS data for guard stage (a) males, (b) females, and crèche stage (c) males and (d) females. Exponential curves represent fitted values from the minimal models derived from the statistical analyses 
Table 3. ANOVA for fixed effects in the minimal models that fitted the data: (a) foraging trip duration during chick rearing as a function of departure weight, season and sex; (b) departure weight during chick rearing as a function of chronological date, season and sex; and (c) foraging trip duration during chick rearing as a function of chronological date, season and sex

\begin{tabular}{|c|c|c|c|}
\hline Source & df & $F$ & $\mathrm{p}$-value \\
\hline \multicolumn{4}{|l|}{ (a) Foraging trip duration } \\
\hline \multicolumn{4}{|l|}{ Guard stage } \\
\hline Departure weight & 1,5178 & 146.03 & $<0.0001$ \\
\hline Season & 11,1673 & 16.88 & $<0.0001$ \\
\hline Sex & 1,1673 & 113.8 & $<0.0001$ \\
\hline Departure weight $\times$ Season & 11,5178 & 6.05 & $<0.0001$ \\
\hline \multicolumn{4}{|l|}{ Crèche stage } \\
\hline Departure weight & 1,8591 & 132.27 & $<0.0001$ \\
\hline Season & 10,1542 & 15.16 & $<0.0001$ \\
\hline Sex & 1,1542 & 11.69 & 0.001 \\
\hline Departure weight $\times$ Season & 10,8591 & 5.78 & $<0.0001$ \\
\hline \multicolumn{4}{|l|}{ (b) Departure weight } \\
\hline \multicolumn{4}{|l|}{ Guard stage } \\
\hline Chronological date & 1,5177 & 2286.8 & $<0.0001$ \\
\hline Season & 11,1673 & 29.1 & $<0.0001$ \\
\hline Sex & 1,1673 & 517.6 & $<0.0001$ \\
\hline Chronological date $\times$ Season & 11,5177 & 23.9 & $<0.0001$ \\
\hline Chronological date $\times$ Sex & 1,5177 & 187 & $<0.0001$ \\
\hline \multicolumn{4}{|l|}{ Crèche stage } \\
\hline \multicolumn{4}{|l|}{ Source } \\
\hline Chronological date & 1,8591 & 256.3 & $<0.0001$ \\
\hline Season & 10,1542 & 15.4 & $<0.0001$ \\
\hline Sex & 1,1542 & 365.8 & $<0.0001$ \\
\hline Chronological date $\times$ Season & 10,8591 & 12 & $<0.0001$ \\
\hline \multicolumn{4}{|l|}{ (c) Foraging trip duration } \\
\hline \multicolumn{4}{|l|}{ Guard stage } \\
\hline Chronological date & 1,6690 & 8.2 & 0.004 \\
\hline Season & 11,1899 & 22.3 & $<0.0001$ \\
\hline Sex & 1,1899 & 282 & $<0.0001$ \\
\hline Chronological date $\times$ Season & 11,6690 & 10 & $<0.0001$ \\
\hline \multicolumn{4}{|l|}{ Crèche stage } \\
\hline \multicolumn{4}{|l|}{ Source } \\
\hline Chronological date & 1,11751 & 552.62 & $<0.0001$ \\
\hline Season & 10,1611 & 17.11 & $<0.0001$ \\
\hline Sex & 1,1611 & 49.03 & $<0.0001$ \\
\hline Chronological date $\times$ Season & 10,11751 & 26.54 & $<0.0001$ \\
\hline
\end{tabular}

starved to death during the guard period that season (Kerry et al. 1995a).

Analyses of departure weight as a function of chronological date showed a difference between the guard and crèche stages of chick rearing. In the guard stage departure weight declined as time progressed and the rate of decline varied with both season and sex (Fig. 7a,b). Penguins were generally at their lightest weight at the beginning of the crèche stage and then showed an increase in weight over time (Fig. $7 \mathrm{c}, \mathrm{d}$ ). Males and females showed the same rate of change in the crèche stage. Analysis of variance results for the
Table 4. (a) Estimated percentage increase in foraging trip duration for each $100 \mathrm{~g}$ reduction in departure weight. (b) Estimated percentage change in foraging trip duration for each week into the stage of breeding. Numbers of foraging trips are provided in brackets. Asterisks indicate significant differences from 0 , where ${ }^{*} 0.01<\mathrm{p}<0.05,{ }^{* *} \mathrm{p}<0.01$

\begin{tabular}{|c|c|c|}
\hline & Guard & Crèche \\
\hline \multicolumn{3}{|c|}{ (a) Foraging trip duration and depature weight } \\
\hline $1991-92$ & $4.0(551)^{* *}$ & $4.5(669)^{* *}$ \\
\hline $1992-93$ & $1.4(514)^{*}$ & $6.0(843)^{* *}$ \\
\hline $1993-94^{\mathrm{a}}$ & $0.3(276)$ & $4.4(1249)^{* *}$ \\
\hline $1994-95^{\mathrm{b}}$ & $5.2(142)^{* *}$ & No chicks alive \\
\hline $1995-96^{\mathrm{b}}$ & $1.8(358)^{*}$ & $2.8(422)^{*}$ \\
\hline $1996-97^{\mathrm{a}}$ & $-0.6(660)$ & $2.7(1111)^{* *}$ \\
\hline $1997-98$ & $2.2(328)^{* *}$ & $3.2(343)$ \\
\hline $1998-99^{\mathrm{b}}$ & $4.3(215)^{* *}$ & $7.7(324)^{* *}$ \\
\hline $1999-00$ & $3.0(527)^{* *}$ & $6.4(644)^{* *}$ \\
\hline $2000-01$ & $2.7(858)^{* *}$ & $2.8(1724)^{* *}$ \\
\hline $2001-02^{\mathrm{a}}$ & $-0.4(1453)$ & $0.3(1657)$ \\
\hline $2002-03$ & $1.5(994)^{* *}$ & $4.9(1170)^{* *}$ \\
\hline \multicolumn{3}{|c|}{ (b) Foraging trip duration and stage of breeding } \\
\hline $1991-92$ & $0.0(735)$ & $-13.0(906)^{* *}$ \\
\hline $1992-93$ & $-5.0(690)$ & $-22.0(1098)^{* *}$ \\
\hline $1993-94^{\mathrm{a}}$ & $2.0(464)$ & $-12.0(2507)^{* *}$ \\
\hline $1994-95^{\mathrm{b}}$ & $48.0(384)^{* *}$ & No chicks alive \\
\hline $1995-96^{\mathrm{b}}$ & $12.0(591)^{* *}$ & $-20.0(591)^{* *}$ \\
\hline $1996-97^{a}$ & $-6.0(745)$ & $-1.0(1479)$ \\
\hline $1997-98$ & $7.0(539)^{*}$ & $-27.0(454)^{* *}$ \\
\hline $1998-99^{b}$ & $26.0(338)^{* *}$ & $-41.0(463)^{* *}$ \\
\hline 1999-00 & $-1.0(592)$ & $-21.0(730)^{* *}$ \\
\hline $2000-01$ & $3.0(951)$ & $-19.0(1954)^{* *}$ \\
\hline $2001-02^{\mathrm{a}}$ & $-2.0(1506)$ & $-4.0(1931)$ \\
\hline $2002-03$ & $0.0(1079)$ & $-27.0(1272)^{* *}$ \\
\hline \multicolumn{3}{|c|}{$\begin{array}{l}\text { a Seasons in which breeding success was }>0.9 \text { chicks } \\
\text { crèched per nest }\end{array}$} \\
\hline \multicolumn{3}{|c|}{$\begin{array}{l}{ }^{\mathrm{b}} \text { Seasons in which breeding success was }<0.4 \text { chicks } \\
\text { crèched per nest }\end{array}$} \\
\hline
\end{tabular}

minimal models for guard and crèche are provided in Table 3b. During the guard stage females lost body weight at average rates ranging from 57 to $309 \mathrm{~g} \mathrm{wk}^{-1}$ across seasons. Males lost weight at an average of $119 \mathrm{~g} \mathrm{wk}^{-1}$ more than females, varying from 176 to $428 \mathrm{~g} \mathrm{wk}^{-1}$ across years (Table 5). These rates were significantly different from zero in all years at the 0.01 level. Rates of weight gain during crèche were lower than the rates of loss in the guard period, ranging from 0 to $103 \mathrm{~g} \mathrm{wk}^{-1}$ with no sex differences and significance at the 0.05 level in all seasons except 2000-01 (Table 5).

Foraging trip durations remained stable or increased over the guard stage and generally decreased during the crèche stage after peaking early in the latter period (Fig. 8, Table 3c). Rates of increase during the guard stage were significantly different from zero in 1994-95, 1995-96 and 1998-99 (Table 
Table 5. Estimated change in departure weight $(\mathrm{g})$ for each week into the stage of breeding

\begin{tabular}{|c|c|c|c|}
\hline & Male & Female & Crèche \\
\hline 1991-92 & $-176(257)^{* *}$ & $-57(294)^{* *}$ & $42(669)^{* *}$ \\
\hline $1992-93$ & $-288(253)^{* *}$ & $-169(261)^{* *}$ & $84(843)^{* * *}$ \\
\hline $1993-94^{\mathrm{a}}$ & $-327(135)^{* *}$ & $-207(141)^{* *}$ & $51(1249)^{* *}$ \\
\hline $1994-95^{\mathrm{b}}$ & $-398(68)^{* *}$ & $-279(74)^{* *}$ & No chicks alive \\
\hline $1995-96^{b}$ & $-428(181)^{* *}$ & $-309(177)^{* *}$ & $98(422)^{* *}$ \\
\hline $1996-97^{a}$ & $-216(328)^{* *}$ & $-97(332)^{* *}$ & $100(1111)^{* *}$ \\
\hline $1997-98$ & $-326(177)^{* *}$ & $-206(151)^{* *}$ & $36(343)^{*}$ \\
\hline $1998-99^{b}$ & $-360(122)^{* *}$ & $-241(93)^{* *}$ & $103(324)^{* *}$ \\
\hline $1999-00$ & $-330(273)^{* *}$ & $-211(254)^{* *}$ & $85(644)^{* *}$ \\
\hline $2000-01$ & $-361(438)^{* *}$ & $-242(420)^{* *}$ & $0(1724)$ \\
\hline $2001-02^{\mathrm{a}}$ & $-213(720)^{* *}$ & $-94(733)^{* *}$ & $43(1657)^{* *}$ \\
\hline $2002-03$ & $-304(486)^{* *}$ & $-185(508)^{* *}$ & $19(1170)^{*}$ \\
\hline \multicolumn{4}{|c|}{$\begin{array}{l}\text { a Seasons in which breeding success was }>0.9 \text { chicks } \\
\text { crèched per nest }\end{array}$} \\
\hline \multicolumn{4}{|c|}{$\begin{array}{l}\text { bSeasons in which breeding success was }<0.4 \text { chicks } \\
\text { crèched per nest }\end{array}$} \\
\hline
\end{tabular}

$4 \mathrm{~b}$ ), all seasons of poor breeding success (Irvine et al. 2000). Rates of decline in foraging trip duration during the crèche stage varied among years. Long trips early in the crèche stage (Fig. 8) were consistent with results from the tracking study, although short trips were less commonly carried out by tracked penguins later in the crèche period compared to non-instrumented birds recorded by the APMS. This may be indicative of an instrument effect that was not statistically significant when equal numbers of trips of instrumented and control birds were compared (see next section).
The above analyses showed that in most seasons, except those of highest breeding success, penguins (particularly males) lost body condition during the guard stage whilst feeding their chicks frequently and alternating duties with their partners. Penguins generally regained some weight during the crèche stage once freed from the constraints of the nest. Foraging trip durations and distances travelled from the colony peaked early in the crèche stage and birds maintained their own body condition at both stages of chick rearing by increasing their foraging durations (and thus distances travelled from the colony) whenever their body mass was low.

\section{Instrument effects}

No significant differences in trip duration between PTT carriers and non-instrumented birds were found in any season except 1998-99 and 2000-01 when trips of instrumented birds were longer than those of controls (medians of 98.1 and $60.2 \mathrm{~h}$ respectively in 1998-99, Mann-Whitney rank sum test: $t=520, \mathrm{n}=20$, $\mathrm{p}=0.003$; medians of 41.9 and $26.6 \mathrm{~h}$ respectively in $2000-01, t=7465, \mathrm{n}=82, \mathrm{p}=0.021$ ). Further analysis showed that the difference during the latter season was restricted to the crèche stage, whilst in 1998-99 differences were present in both guard and crèche stages of breeding. The overall ratio of short $(<40 \mathrm{~h})$ to long ( $>40 \mathrm{~h}$ ) trips (as defined in Clarke et al. 1998) carried out by tracked birds was 1:2, whilst in the APMS data set as a whole this ratio is approximately $2: 1$ (J. Clarke unpubl. data).

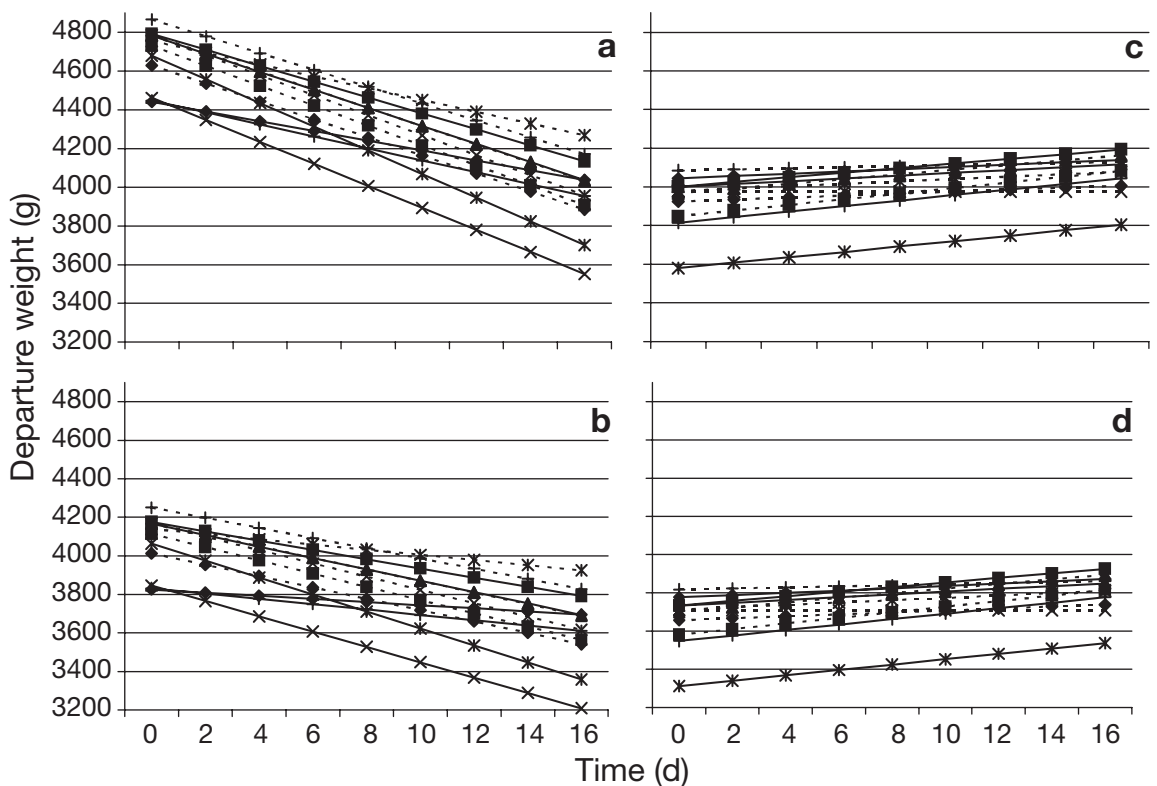

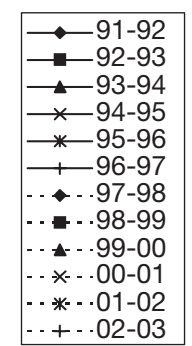

Fig. 7. Pygoscelis adeliae. Relationship between departure weight and days into the guard and crèche stages for 12 seasons of APMS data for guard stage (a) males, (b) females, and crèche stage (c) males and (d) females. Lines represent fitted values from the output of the minimal models derived from the statistical analyses 


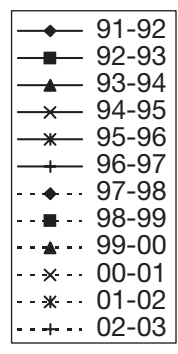

Fig. 8. Pygoscelis adeliae. Relationship between foraging trip duration and days into the guard and crèche stages for 12 seasons of APMS data for guard stage (a) males, (b) females, and crèche stage (c) males and (d) females. Exponential curves represent fitted values from the output of the minimal models derived from the statistical analyses
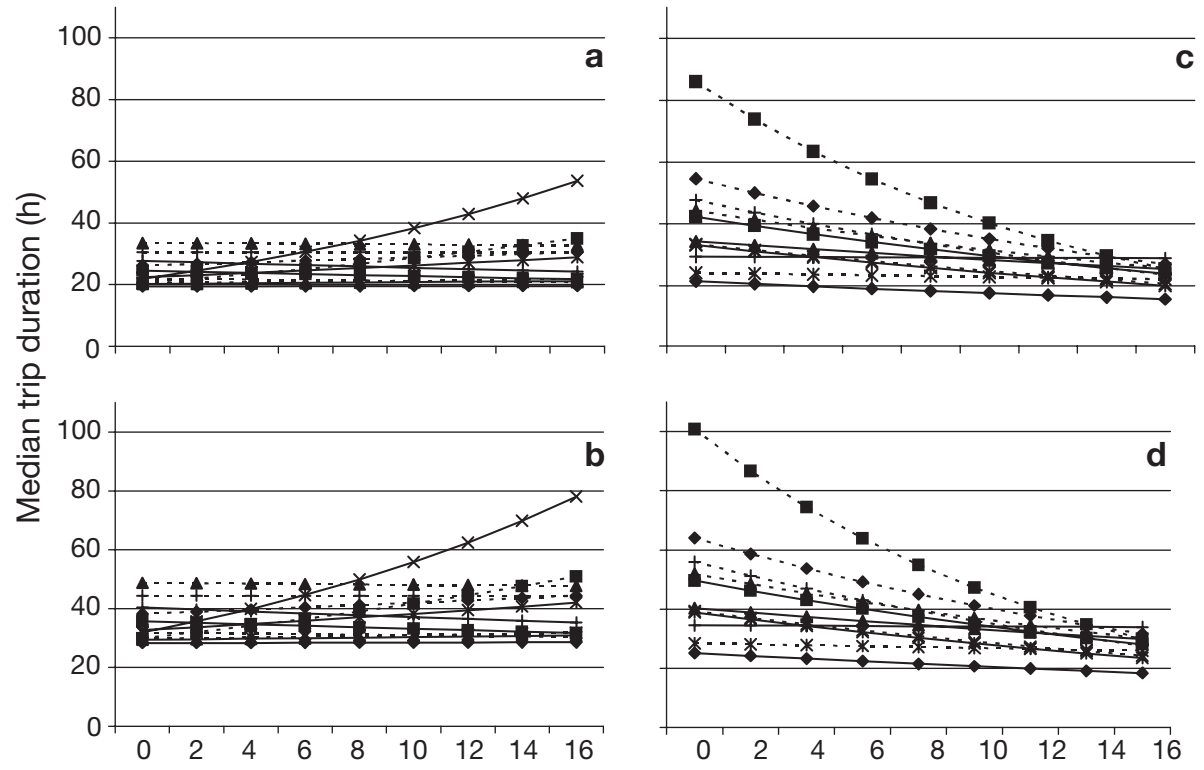

Time $(d)$

\section{DISCUSSION}

\section{Instrument effects}

It is unlikely that the consistent increase in foraging range between guard and crèche phases documented in this study was due to instrument effects because the crèche stage was influenced differently than the guard stage only in 2000-01. Results were consistent with previous work at this location (Clarke \& Kerry 1994) and with that of Ballard et al. (2001), both of which found that individual variation in foraging duration during chick rearing precluded detection of significant instrument effects on a within season basis. However, the greater tendency of instrument carriers to make trips in excess of $40 \mathrm{~h}$ raises the possibility that birds encumbered by satellite trackers may need to carry out long trips more frequently to maintain body condition than do birds not carrying instruments. This corresponds with the findings of Watanuki et al. (1992), Hull (1997) and Bost et al. (2004), who observed that instrument effects were most pronounced at times of year when foraging penguins are most energetically stressed.

\section{Foraging ranges during breeding and environmental constraints}

The distribution of foraging penguins during the breeding season can be expected to correlate with the distribution of their prey within constraints imposed by physical barriers such as sea ice and the need to return regularly to the colony to provision offspring. Adélie penguin foraging distances vary widely depending on colony location and stage of breeding. For example, penguins provisioning chicks at Hukuro Cove $\left(69^{\circ} 00^{\prime} \mathrm{S}, 39^{\circ} 39^{\prime} \mathrm{E}\right)$ limit their foraging to a $5 \mathrm{~km}$ radius throughout chick rearing (Kato et al. 2003), whilst those at Signy Island $\left(60^{\circ} 43^{\prime} \mathrm{S}, 45^{\circ} 34^{\prime} \mathrm{W}\right)$ range up to $177 \mathrm{~km}$ in the crèche stage (Lynnes et al. 2002). In this study the foraging ranges of Adélie penguins at Béchervaise Island changed as the breeding season progressed in all years examined. Penguins travelled long distances during incubation and shorter distances during chick rearing. Adult foraging ranges typically expanded in both distance and area as chicks progressed from guard to crèche stages, and were greater still during the period when birds accumulate fat reserves prior to carrying out their annual moult.

Adélie penguins are considered ice-obligate over winter (Fraser \& Trivelpiece 1996, Ainley 2002) and are closely associated with sea ice in summer (Trivelpiece \& Fraser 1996, Ainley 2002). During incubation this species commonly forages $200 \mathrm{~km}$ or more from its breeding colonies (Davis \& Miller 1992, Kerry et al. 1995a). Proximity of Adélie penguin colonies to polynyas provides crucial access to foraging grounds during spring as well as opportunities for faster travelling rates and wider distribution of foraging birds (Fraser \& Trivelpiece 1996, Arrigo \& van Dijken 2003, Ainley et al. 2004). Penguins tracked during incubation in this study walked directly to the nearest margin of the Taylor Glacier polynya before moving northwards into the pack ice, using the polynya as access to the pack ice zone rather than as a foraging locality per 
se. Like Adélie penguins tracked from Inexpressible Island ( $74^{\circ} 54^{\prime} \mathrm{S}, 163^{\circ} 39^{\prime} \mathrm{E}$ ) in the Ross Sea (S. Olmastroni pers. comm.), the Béchervaise Island penguins foraged around the margin of the polynya, remaining in association with the ice rather than spending time in open water.

Large Adélie penguin breeding colonies are only found in regions where fast ice typically breaks out from the Antarctic coastline before or soon after chicks hatch (Trivelpiece \& Fraser 1996, Ainley 2002). The presence of excessive fast ice or heavy pack ice during the chick rearing period restricts access to prey, resulting in reduced breeding success in years of extensive ice cover (Yeates 1968, Ainley \& LeResche 1973, Spurr 1975, Whitehead et al. 1990, Irvine et al. 2000, Clarke et al. 2002). In the Mawson region, where a submarine canyon facilitates upwelling of warm water, pack ice is limited in extent by early January and the distance to the edge of the fast ice reduced in most years (Michael et al. 2003). Penguins return to the colony at 1 to $3 \mathrm{~d}$ intervals to feed their growing chicks and alternate guard duties with their mates. Their foraging range is constrained at this time by access to food and the requirement for regular provisioning of offspring.

The distribution and abundance of krill Euphausia superba and other zooplankton in the Mawson region is patchy and highly variable over short temporal and small spatial scales in summer (Hosie et al. 1988, Hosie et al. 1997, Pauly et al. 2000, S. Nicol unpubl. data). Although some local foraging took place, the penguins in this study concentrated much of their guard and crèche stage foraging activity along the continental shelf break where E. superba aggregate in greatest concentrations (Higginbottom et al. 1988, Hosie et al. 1988), and large krill predominate in summer (Lascara et al. 1999, Nicol et al. 2000, Salihoglu et al. 2001). Because the shelf break lies 100 to $110 \mathrm{~km}$ from the Mawson coast, penguins are required to travel this distance to reach reliable foraging grounds, necessitating trips of three or more days in duration.

Penguins from Béchervaise Island travel further to reach the productive foraging grounds at the shelf break than birds at other locations where the shelf break is closer (Lishman 1985), neritic species more abundant (Ainley et al. 1998, 2004), or Euphausia superba found closer to the coast (Watanuki et al. 1994). The range and distance travelled by penguins at each of these colonies is highly dependent on the environmental features of the particular area, and how these environmental features influence prey distribution and the penguins' access to prey. For example, the distribution of foraging penguins during the guard stage in this study was centred over a bathymetric canyon where zooplankton productivity is likely to be enhanced.
Adélie penguins are known to moult on large ice floes, ice bergs and sheltered areas of land (Ainley 2002), but how far they range from their breeding sites at this time of year is virtually unknown. Penguins foraging prior to moult are no longer provisioning offspring and are thus free to travel further from the colony to search for food. In this study birds foraged predominantly in waters over the continental shelf towards Enderby Land in the west, and north of Cape Darnley in the east. It is possible that by autumn, when sea ice is minimal, penguins are able to exploit krill patches associated with remnant ice and late summer phytoplankton blooms to the west of the Mawson region where fast ice persists until late summer (Michael et al. 2003). The region to the north of Cape Darnley, on the other hand, is known to be an area of high productivity (Quilty et al. 1985), even in seasons where krill is scarce elsewhere along the coast ( $\mathrm{S}$. Nicol unpubl. data). Concentration of penguin foraging activity in this locality is thus unsurprising, and there is also limited evidence that birds from Scullin \& Murray Monoliths feed here on a regular basis (Kerry et al. 1997).

\section{Partitioning of resources during chick rearing and life history constraints}

Although a decrease in penguin foraging range between the incubation and chick rearing stages of breeding is well documented (Hull et al. 1997, Kerry et al. 1997, Barlow \& Croxall 2002), variations in range post hatch are less consistent. Increasing foraging ranges as chick rearing progresses are reported for macaroni, royal and Adélie penguins at a number of locations (Hull et al. 1997, Watanuki et al. 1999, Wienecke et al. 2000, Barlow \& Croxall 2002, Lynnes et al. 2002, Kato et al. 2003, Ainley et al. 2004), including Béchervaise Island (this study) but apparently not at others (Lishman 1985, Trivelpiece et al. 1987, Wienecke et al. 2000). Ainley et al. (2004) suggested that the foraging range expansion observed at Ross Island resulted from intraspecific competition and consequent effects on foraging effort. Alonzo et al.'s (2003) modelling study also predicted an increase in offshore foraging if prey were depleted close to the colony. Increasing energy demands as chick rearing progresses (Culik 1994) combined with local food depletion due to intraspecific competition might be expected to influence both foraging strategies and the distribution of foraging birds.

The Béchervaise Island colony is a small subcolony within the Mawson region where approximately 55000 pairs breed along a $10 \mathrm{~km}$ stretch of coastline. With this number of penguins foraging in the area, 
prey supplies could potentially be depleted within the vicinity of the colonies by the end of the guard stage. In addition, an estimated 66000 pairs of Adélie penguins breed on the Rookery Islands (Woehler 1993, Woehler et al. 2001) situated less than $20 \mathrm{~km}$ west of Mawson. Competition between these two colonies for limited resources may exacerbate the challenge of meeting provisioning requirements as the breeding season progresses.

Many flying seabirds show a dual foraging strategy during chick rearing whereby they use a combination of long and short foraging trips as a means of partitioning energy resources, maximising use of distant food resources for self maintenance and thereby reducing intraspecific competition close to the colony (Chaurand \& Weimerskirch 1994, Weimerskirch et al. 1994, Weimerskirch 1998). A single year study on Adélie penguins in the Mawson region (Clarke 2001) showed that breeding birds carried out short trips to provision chicks at the expense of stored body reserves and that these reserves gradually declined throughout the guard stage of chick rearing. Watanuki et al. (2002) found a similar relationship between departure mass and trip duration at 2 other locations in East Antarctica, and Culik (1994) observed declines in body weight during the guard period.

In this multi-year study we have shown that Adélie penguins typically carry out longer foraging trips when their weight is low compared to when they are in better body condition. Only in seasons of high breeding success does this relationship fail to hold, suggesting that plentiful food supplies close to the colony allow birds to maintain condition without lengthening their foraging trips. Adults lose weight during the guard stage, and foraging durations increase during years when feeding conditions are apparently poor (low chick survival). Trip durations generally peak in the early crèche period when adult body condition is lowest and chicks can be left unguarded whilst both parents forage. Freedom from the constraint of guard duty enables adults to forage simultaneously and regain some of their lost body condition without a reduction in overall chick feeding frequency.

In their modelling study, Alonzo et al. (2003) found that penguins adopting a time minimising strategy foraged close to the colony unless krill abundance was low, as tends to be the case in neritic waters close to Mawson during summer. More penguins were predicted to forage further offshore when penguins were food maximising. Although their model used the example of a simple penguin-krill system operating in waters between the coast and the edge of the continental shelf, it was based on a more general framework designed to examine interactions between species (Alonzo 2002). The behaviour of Adélie penguins in the Mawson region is consistent with penguins adopting a time minimising foraging rule during chick rearing except when their body weight is low. The latter occurs most commonly during the early crèche stage when frequent provisioning rates are less critical and access to distant more productive foraging grounds advantageous for body condition maintenance. Our results provide empirical support for the proposition of Alonzo et al. (2003) that Adélie penguin distribution during chick rearing in regions where inshore resources are limiting is a result of foraging rules adopted by the birds under the constraints of competing demands for self maintenance and reproduction.

Acknowledgements. We are indebted to the dedicated assistance of a number of field staff, particularly L. Irvine, M. Tierney, H. Gardner and R. Lawless. We are grateful to G. McPherson for statistical assistance, D. Watts for development of customised software for processing of ARGOS data and D. Smith for GIS advice. The program was instigated and overseen by K. Kerry, now retired from the Australian Antarctic Division, and supported by members of the Australian National Antarctic Research Expeditions (ANARE). Attachment of instruments to penguins and injection of identification transponders were carried out with approval from the Australian Antarctic Division's Animal Ethics Committee. Comments from C. Southwell and the anonymous referees greatly improved the manuscript.

\section{LITERATURE CITED}

Ainley DG (2002) The Adélie penguin — bellwether of climate change. Columbia University Press, New York

Ainley DG, LeResche RE (1973) The effects of weather and ice conditions on breeding in Adélie penguins. Condor 75 : 235-239

Ainley DG, Wilson PR, Barton KJ, Ballard G, Nur N, Karl B (1998) Diet and foraging effort of Adélie penguins in relation to pack-ice conditions in the southern Ross Sea. Polar Biol 20:311-319

Ainley DG, Ribic CA, Ballard G, Heath S and 5 others (2004) Geographic structure of Adélie penguin populations: overlap in colony-specific foraging areas. Ecol Monogr 74: $159-178$

Alonzo SH (2002) State-dependent habitat selection games between predators and prey: the importance of behavioural interactions and expected lifetime reproductive success. Evol Ecol Res 4:759-778

Alonzo SH, Switzer PV, Mangel M (2003) Ecological games in space and time: the distribution and abundance of Antarctic krill and penguins. Ecology 84:1598-1607

Arrigo KR, van Dijken GL (2003) Phytoplankton dynamics within 37 Antarctic coastal polynyas. J Geophys Res 108, 3271, doi:10.1029/2002JC002739

Ballard G, Ainley DG, Ribic CA, Barton KJ (2001) Effect of instrument attachment and other factors on foraging trip duration and nesting success of Adélie penguins. Condor 103:481-490

Barlow KE, Croxall JP (2002) Seasonal and interannual variation in foraging range and habitat of macaroni penguins Eudyptes chrysolophus at South Georgia. Mar Ecol Prog Ser 232:291-304 
Bost CA, Charrassin JB, Clerquin Y, Ropert-Coudert Y, Le Maho Y (2004) Exploitation of distant marginal ice zones by king penguins during winter. Mar Ecol Prog Ser 283: 293-297

Chaurand T, Weimerskirch HM (1994) The regular alternation of short and long forging trips in the blue petrel Halobaena caerulea: a previously undescribed strategy of food provisioning in a pelagic seabird. J Anim Ecol 63: 275-282

Clarke J (2001) Partitioning of foraging effort in Adélie penguins provisioning chicks at Béchervaise Island, Antarctica. Polar Biol 24:16-20

Clarke J, Kerry K (1994) The effects of monitoring procedures on Adélie penguins. CCAMLR Sci 1:155-164

Clarke J, Kerry K (1998) Implanted transponders in penguins: implantation, reliability, and long term effects. J Field Ornithol 69:149-159

Clarke J, Manly B, Kerry K, Gardner H, Franchi E, Corsolini S, Focardi S (1998) Sex differences in Adélie penguin foraging strategies. Polar Biol 20:248-258

Clarke J, Kerry K, Irvine L, Phillips B (2002) Chick provisioning and breeding success of Adélie penguins at Béchervaise Island over eight successive seasons. Polar Biol 25: 201-30

Clarke J, Emmerson L, Townsend A, Kerry K (2003) Demographic characteristics of the Adélie Penguin population at Béchervaise Island after 12 years of study. CCAMLR Sci 10:53-74

Culik B (1994) Energy requirements of Pygoscelid penguins: a synopsis. Ber Polarforsch 150:1-76

Culik BM, Bannasch R, Wilson RP (1994) External devices on penguins: how important is shape? Mar Biol 118:353-357

Davis LS, Miller GD (1992) Satellite tracking of Adélie penguins. Polar Biol 12:503-506

Fraser WR, Trivelpiece WZ (1996) Factors controlling the distribution of seabirds: winter-summer heterogeneity in the distribution of Adélie penguin populations. Foundations for Ecological Research west of the Antarctic Peninsula, Antarct Res Ser 70:257-272

Higginbottom IR, Kerry KR, Wayte SE (1988) Hydroacoustic surveys of the distribution and abundance of krill: Prydz Bay region - FIBEX, ADBEX II, and SIBEX II, MV Nella Dan. ANARE Res Notes 62, Antarctic Division, Australia

Hooge PN, Eichenlaub B (1997) Animal movement extension to ArcView version 1.1. US Geological Survey, Anchorage

Hosie GW, Ikeda T, Stolp M (1988) Distribution, abundance and population structure of the Antarctic krill Euphausia superba Dana in the Prydz Bay region, Antarctica. Polar Biol 8:213-224

Hosie GW, Cochran TG, Pauly T, Beaumont KL, Wright SW, Kitchener JA (1997) Zooplankton community structure of Prydz Bay, Antarctica, January-February 1993. Proc NIPR Symp Polar Biol 10:90-133

Hull CL (1997) The effect of carrying devices on breeding royal penguins. Condor 99:530-534

Hull CL, Hindell MA, Michael K (1997) Foraging zones of royal penguins during the breeding season, and their association with oceanographic features. Mar Ecol Prog Ser 153:217-228

Irvine L, Clarke JR, Kerry KR (2000) Poor breeding success of the Adélie penguin at Béchervaise Island in the 1998/99 season. CCAMLR Sci 7:151-167

Kato A, Watanuki Y, Naito Y (2003) Annual and seasonal changes in foraging site and diving behavior in Adélie penguins. Polar Biol 26:389-395

Kerry K, Clarke J, Else G (1993) The use of an automated weighing and recording system for the study of the bio- logy of Adélie penguins (Pygoscelis adeliae). NIPR Symp Pol Biol 6:62-75

Kerry K, Clarke J, Else G (1995a) The foraging range of Adélie penguins at Béchervaise Island, Mac.Robertson Land, Antarctica as determined by satellite telemetry. In: Dann P, Norman I, Reilly P (eds) The penguins. Surrey Beatty \& Sons, Sydney, p 216-243

Kerry K, Clarke J, Gardner H, Murphy R, Hume F, Hodum P (1995b) Adélie penguin chick deaths investigated. ANARE News, Australian Antarctic Division, Hobart, p $18-20$

Kerry K, Clarke J, Eberhard S, Gardner H, Lawless R, Tremont R, Wienecke B (1997) The foraging range of Adélie penguins - implications for CEMP and interactions with the krill fishery. CCAMLR Sci 4:75-87

Lascara CM, Hofmann EE, Ross RR, Quetin LB (1999) Seasonal variability in the distribution of Antarctic krill, Euphausia superba, west of the Antarctic Peninsula. Deep-Sea Res I 46:925-949

Lishman GS (1985) The food and feeding ecology of Adélie penguins Pygoscelis adeliae and chinstrap penguins $P$. antarctica at Signy Island, South Orkney Islands. J Zool Lond 205:245-263

Lynnes AS, Reid K, Croxall JP, Trathan PN (2002) Conflict or co-existence? Foraging distribution and competition for prey between Adélie and chinstrap penguins. Mar Biol 141:1165-1174

Michael K, Hill K, Kerry K, Brolsma H (2003) Atlas of coastal sea ice in Eastern Antarctica. Antarctic CRC Research Report No. 29, Hobart

Nicol S, Kitchener J, King R, Hosie G, de la Mare WK (2000) Population structure and condition of Antarctic krill (Euphausia superba) off East Antarctica (80-150 E) during the Austral summer of 1996/1996. Deep-Sea Res II 47: 2489-2517

Orians GH, Pearson NE (1979) On the theory of central place foraging. In: Horn DH, Mitchell RD, Stairs GR (eds) Analyses of ecological systems. Ohio State University Press, Columbus, $\mathrm{OH}, \mathrm{p}$ 155-177

Pauly T, Nicol S, Higginbottom I, Hosie G, Kitchener J (2000) Distribution and abundance of Antarctic krill (Euphausia superba) off East Antarctica $\left(80-150^{\circ} \mathrm{E}\right)$ during the Austral summer of 1995/1996. Deep-Sea Res II 47:2465-2488

Pyke GH, Pulliam HR, Charnov EL (1977) Optimal foraging: a selective review of theory and tests. Q Rev Biol 52: $137-154$

Quilty PG, Kerry KR, Marchant HJ (1985) A seasonally recurrent patch of Antarctic planktonic diatoms. ANZAAS Search 16:48

Ryan U (1999) Prydz Bay 1:500000 Bathymetric GIS Dataset, Australian Antarctic Data Centre-SnoWhite Metadata. Available at: www.aad.gov.au/default.asp? casid=3802

Salihoglu B, Fraser W, Hofmann EE (2001) Factors affecting fledging weight of Adélie penguin Pygoscelis adeliae chicks: a modeling study. Polar Biol 2001:328-337

Schoener TW (1971) Theory of feeding strategies. Annu Rev Ecol Syst 2:369-404

Service Argos (1996) User manual. Service Argos, Washington, DC

Silverman BW (1986) Density estimation for statistics and data analysis. Chapman \& Hall, London

Sladen WJL (1978) Sexing penguins by cloacascope. Internat Zoo Yearbook 18:77-80

Spurr EB (1975) Breeding of the Adélie penguin Pygoscelis adeliae at Cape Bird. Ibis 117:325-338

Stephens DW, Krebs JR (1986) Foraging Theory. Princeton University Press, Princeton, NJ 
Taylor SS, Leonard ML, Boness DJ, Majluf P (2001) Foraging trip duration increases for Humboldt penguins tagged with recording devices. J Avian Biol 32:369-372

Trivelpiece WZ, Fraser WR (1996) The breeding biology and distribution of Adélie penguins: adaptations to environmental variability. Antarct Res Ser 70:273-285

Trivelpiece WZ, Trivelpiece SC, Volkman NJ (1987) Ecological segregation of Adélie, gentoo, and chinstrap penguins at King George Island, Antarctica. Ecology 62:351-361

Watanuki Y, Mori Y, Naito Y (1992) Adélie penguin parental activities and reproduction: effects of device size and timing of its attachment during chick rearing period. Polar Biol 12:529-544

Watanuki Y, Mori Y, Naito Y (1994) Euphausia superba dominates in the diet of Adélie penguins feeding under fast sea-ice in the shelf areas of Enderby Land in summer. Polar Biol 14:429-432

Watanuki Y, Miyamoto Y, Kato A (1999) Dive bouts and feeding sites of Adélie penguins rearing chicks in an area with fast sea-ice. Waterbirds 22:120-129

Watanuki Y, Kato A, Sato K, Niizuma Y, Bost C-A, Le Maho Y, Naito Y (2002) Parental mass change and food provisioning in Adélie penguins rearing chicks in colonies with contrasting sea-ice conditions. Polar Biol 25:672-681

Weimerskirch H (1998) How can a pelagic seabird provision its chick when relying on a distant food resource? Cyclic attendance at the colony, foraging decision and body condition in sooty shearwaters. J Anim Ecol 67:99-109

Editorial responsibility: Otto Kinne (Editor-in-Chief), Oldendorf/Luhe, Germany
Weimerskirch $\mathrm{H}$, Chastel $\mathrm{O}$, Ackermann L, Chaurand $\mathrm{T}$, Cuenot-Chaillet F, Kindermeyer X, Judas J (1994) Alternate long and short foraging trips in pelagic seabird parents. Anim Behav 47:472-476

Whitehead MD, Johnstone GW, Burton HR (1990) Annual fluctuations in productivity and breeding success of Adélie penguins and fulmarine petrels in Prydz Bay, East Antarctica. In: Kerry KR, Hempel G (eds) Antarctic ecosystems, ecological change and conservation. Springer-Verlag, Berlin, p 214-223

Wienecke BC, Lawless R, Rodary D, Bost CA and 5 others (2000) Adélie penguin foraging behaviour and krill abundance along the Wilkes and Adélie Land coast, Antarctica. Deep-Sea Res II 47:2573-2587

Woehler E (1993) The distribution and abundance of Antarctic and Sub-Antarctic penguins. SCAR, Cambridge

Woehler E, Cooper J, Croxall JP, Fraser WR and 9 others (2001) A statistical assessment of the status and trends of Antarctic and Sub-Antarctic seabirds. SCAR, Cambridge

Worton BJ (1989) Kernel methods for estimating the utilization distribution in home-range studies. Ecology 70:164-168

Ydenberg RG, Welham CVJ, Schmid-Hempel R, SchmidHempel P, Beauchamp G (1994) Time and energy constraints and the relationships between currencies in foraging theory. Behav Ecol 5:28-34

Yeates GW (1968) Studies on the Adélie penguin at Cape Royds 1964-65 and 1965-66. NZ J Mar Freshw Res Sept: 472-496

Submitted: July 5, 2004; Accepted: September 7, 2005

Proofs received from author(s): February 21, 2006 